\title{
Effect of pelvic floor muscle training compared with watchful waiting in older women with symptomatic mild pelvic organ prolapse: randomised controlled trial in primary care
}

\begin{abstract}
Objective To compare the effects of pelvic floor muscle training and watchful waiting on pelvic floor symptoms in a primary care population of women aged 55 years and over with symptomatic mild pelvic organ prolapse.

Design Randomised controlled trial.

Setting Dutch primary care.

Participants Women aged 55 years or over with symptomatic mild prolapse (leading edge above the hymen) were identified by screening. Exclusion criteria were current prolapse treatment or treatment in the previous year, malignancy of pelvic organs, current treatment for another gynaecological disorder, severe/terminal illness, impaired mobility, cognitive impairment, and insufficient command of the Dutch language. Interventions Pelvic floor muscle training versus watchful waiting.

Main outcome measures The primary outcome was change in bladder, bowel, and pelvic floor symptoms measured with the Pelvic Floor Distress Inventory-20 (PFDI-20), three months after the start of treatment. Secondary outcomes were changes in condition specific and general quality of life, sexual function, degree of prolapse, pelvic floor muscle function, and patients' perceived change in symptoms.

Results Of the 287 women who were randomised to pelvic floor muscle training $(n=145)$ or watchful waiting $(n=142), 250(87 \%)$ completed follow-up. Participants in the intervention group improved by (on average) 9.1 (95\% confidence interval 2.8 to 15.4 ) points more on the PFDI-20 than did participants in the watchful waiting group $(P=0.005)$. Of women in the pelvic floor muscle training group, $57 \%(82 / 145)$ reported an improvement in overall symptoms from the start of the study compared with $13 \%(18 / 142)$ in the watchful waiting group $(P<0.001)$. Other secondary outcomes showed no significant difference between the groups.
\end{abstract}

Conclusions Although pelvic floor muscle training led to a significantly greater improvement in PFDI-20 score, the difference between the groups was below the presumed level of clinical relevance (15 points).

Nevertheless, $57 \%$ of the participants in the intervention group reported an improvement of overall symptoms. More studies are needed to identify factors related to success of pelvic floor muscle training and to investigate long term effects.

Trial registration Dutch Trial Register (www.trialregister.nl) identifier: NTR2047.

\section{Introduction}

Pelvic organ prolapse is a common condition characterised by descent of the anterior or posterior vaginal wall, the uterus, or the vaginal vault (after hysterectomy). ${ }^{1}$ In a Dutch community survey, $75 \%$ of women aged $45-85$ years had some degree of prolapse. $^{2}$ The prevalence of typical symptoms of prolapse (seeing or feeling a vaginal bulge) is reported to be about $3-12 \% .^{23}$ Typical prolapse symptoms are thought to emerge when the leading edge of the prolapse is at or below the hymen. ${ }^{4}$ Women with milder forms of prolapse more often experience other common prolapse related symptoms such as pelvic pressure/heaviness or pelvic pain and urinary or bowel symptoms. Treatment options include conservative management (pelvic floor muscle training or pessary treatment) and surgical correction. However, surgery is associated with several problems. Comorbidity and frailty can make surgery undesirable, and risks of complications and recurrence are considerable. Finally, costs for prolapse related surgery are high and are expected to substantially increase owing to the ageing population and the higher prevalence of prolapse in older women. ${ }^{6}$ 
As women with mild prolapse often experience mild symptoms, surgery is generally not an option. However, evidence suggests that women with symptomatic mild prolapse might benefit from pelvic floor muscle training. ${ }^{78}$ There are two main hypotheses on how pelvic floor muscle training may be effective in the treatment of prolapse: descent of the pelvic floor is prevented by teaching women to consciously contract their pelvic floor muscles before and during any increase in abdominal pressure; and structural support of the pelvic floor is improved by the performance of pelvic floor muscle exercises, and, as a result, the pelvic organs are held in place better. ${ }^{9}$ Beneficial effects of pelvic floor muscle training in symptomatic stage 1 and/or 2 prolapse were shown in three small studies, of which two were pilot studies ${ }^{78}$ and the other was of moderate methodological quality. ${ }^{10}$ Other studies investigating the effect of pelvic floor muscle training on prolapse also included women without symptoms, women with more severe stage prolapse (at or below the hymen), or both. ${ }^{11-14}$

Pelvic floor muscle training could typically be applied in primary care. However, high quality studies on the effectiveness of pelvic floor muscle training in women with symptomatic (mild) prolapse in this setting are lacking. The aim of this study was to compare the effects of pelvic floor muscle training and watchful waiting on pelvic floor symptoms in a primary care population of women aged 55 years or over with symptomatic mild prolapse.

\section{Methods}

This was a randomised controlled trial comparing pelvic floor muscle training and watchful waiting in women aged 55 years or over with symptomatic mild pelvic organ prolapse. All participants gave written informed consent. The study design has been published in detail elsewhere. ${ }^{15}$

\section{Participants}

Participants were recruited from 15 Dutch general practices between 14 October 2009 and 19 October 2012. Participating general practitioners selected all women aged at least 55 years who did not meet the study's exclusion criteria. These included current prolapse treatment or treatment in the previous year, pelvic organ malignancy, current treatment for another gynaecological disorder, severe/terminal illness, impaired mobility, cognitive impairment, and insufficient command of the Dutch language. The remaining women received a postal five item screening questionnaire (web appendix 1) asking about vaginal bulging, pelvic heaviness, urinary incontinence, and vaginal splinting to assist micturition or defecation. Women who responded positively to one or more screening questions were invited to fill in another questionnaire and visit for a baseline assessment.

A standardised interview about demographics and medical and obstetric history was performed. Additionally, all women underwent a physical examination and urinalysis for urinary tract infection. When urinalysis showed a urinary tract infection, participants were treated with antibiotics and afterwards filled in a new questionnaire (which replaced the original baseline questionnaire). The baseline physical examination comprised measurement of post-void residual volume with an abdominal ultrasound (BladderScan), evaluation of pelvic floor muscle function, ${ }^{16}$ and Pelvic Organ Prolapse Quantification (POP-Q) measurement. ${ }^{17}$ Physical examinations were performed by research physicians who were trained in POP-Q measurement and pelvic floor muscle function assessment by an experienced urogynaecologist. Women with mild prolapse, defined as the leading edge of the prolapse staying above the hymen (POP-Q stage 1 and mild stage 2 ), were eligible for randomisation.

\section{Interventions}

\section{Pelvic floor muscle training}

Pelvic physiotherapists registered with the Dutch Pelvic Physiotherapists' Organisation treated all participants randomised to pelvic floor muscle training. These physiotherapists complete a three year specialisation course in the diagnosis and treatment of pelvic floor disorders. Pelvic floor muscle training was provided individually in face-to-face contacts combined with home exercises. The pelvic physiotherapists recorded the treatment modalities and the number of treatment sessions for each participant. For all participants, the intervention started with an explanation of the function of the pelvis and the pelvic floor and about pelvic floor dysfunctions; illustrations and three dimensional models of the pelvis were used. Pelvic floor muscle function was assessed by digital palpation. During this examination, the physiotherapists also checked whether participants were able to correctly contract ("squeeze and lift") and relax their pelvic floor muscles. If necessary, they used breathing exercises to increase awareness of the pelvic floor. Participants who were not able to contract or relax their pelvic floor muscles were first instructed how to do this by being given feedback during digital palpation or, if necessary, by application of myofeedback or electrical stimulation. Participants who were able to control their pelvic floor consciously but whose pelvic floor muscles were too weak started training their pelvic floor by doing exercises. All participants started with the same basic exercise scheme, to which specific exercises could be added (web appendix 2).

The exercise programme was individualised and was modified at each appointment on the basis of examination findings. In cases of an overactive pelvic floor, the focus of the exercises was on relaxation rather than on contraction and, if necessary, general relaxation exercises were used. All participants were taught to contract their pelvic floor muscles before and during any increases in abdominal pressure ("the knack"), and attention was paid to lifestyle (diet, body weight) and toilet habits (web appendix 2). Initially, participants visited the pelvic physiotherapist on a weekly basis, but when they were able to correctly contract and relax their pelvic floor muscles the intervals between appointments were extended (two to three weeks). Participants were encouraged to continue practising at home three to five times a week, twice or three times each day.

\section{Watchful waiting}

Participants randomised to watchful waiting received no treatment and no recommendations.

\section{Follow-up}

Participants were scheduled for a follow-up appointment with the research physician three months after the start of treatment (or, in case of watchful waiting, three months after randomisation). During the study period, participants were allowed to visit their general practitioner or other caregiver for any symptoms of prolapse; such visits were recorded at follow-up.

\section{Outcomes}

The primary outcome of this trial was change in bladder, bowel, and pelvic floor symptoms three months after the start of treatment. Secondary outcomes were changes in condition 
specific and general quality of life, sexual functioning, degree of prolapse, pelvic floor muscle function, and patients' perceived change in symptoms from the start of the study.

\section{Measurements}

We measured change in bladder, bowel, and pelvic floor symptoms with the Pelvic Floor Distress Inventory-20 (PFDI-20). This patient completed questionnaire comprises three subscales with scores ranging from 0 to 100: the Pelvic Organ Prolapse Distress Inventory-6 assessing prolapse symptoms, the ColoRectal-Anal Distress Inventory-8 assessing colorectal/anal symptoms, and the Urinary Distress Inventory-6 assessing urinary symptoms. A higher PFDI-20 score (sum of three subscale scores, range 0-300) indicates a higher symptom burden. ${ }^{18}$ We measured the effect of bladder, bowel, and pelvic floor symptoms on daily life with the Pelvic Floor Impact Questionnaire-7 (range 0-300, with higher scores indicating greater effect). ${ }^{18}$ We used the Medical Outcomes Study Short Form Health Survey-12 version 1 to measure general quality of life. ${ }^{19}{ }^{20}$ We measured sexual functioning with the Pelvic Organ Prolapse/Incontinence Sexual Function Questionnaire-12 (range 0-48, with higher scores indicating better sexual functioning). ${ }^{21}$ We assessed patients' perceived change in symptoms from the start of the study by using three questions (are symptoms the same/better/worse?) with visual analogue scale scores for improvement/deterioration (on a scale from $0-10)$.

We used the Pelvic Organ Prolapse Quantification system to assess the degree of prolapse at baseline and follow-up. In the POP-Q system, the degree of prolapse of the anterior vaginal wall, the posterior vaginal wall, and the uterus or vaginal vault (when there is a history of hysterectomy) is measured in centimetres, using the hymnal remnants as a reference point. Additionally, the genital hiatus, the perineal body, and the total vaginal length (with the prolapse reduced) are measured. On the basis of these findings, a POP-Q stage (0-4) is calculated for each compartment. The overall POP-Q stage is equal to the POP-Q stage of the most severely prolapsed compartment. ${ }^{17}$ Pelvic floor muscle function was examined by vaginal palpation of the pelvic floor muscles in the lithotomy position. We defined pelvic floor muscle function as normal (voluntary contraction normal/strong, voluntary relaxation complete, involuntary contraction and involuntary relaxation present), underactive (voluntary contraction absent/weak, voluntary relaxation complete, involuntary contraction absent/present, and involuntary relaxation present), overactive (voluntary contraction absent/weak/normal/strong, voluntary relaxation absent/partially present, involuntary contraction and involuntary relaxation absent/present), or inactive (voluntary contraction absent, voluntary relaxation complete, involuntary contraction and involuntary relaxation absent). ${ }^{16}$

\section{Sample size}

To detect a difference of 15 points (25\% reduction in the PFDI-20 score assuming a PDFI-20 baseline score of 60 points and no change in the watchful waiting group ${ }^{15}$ ) with a standard deviation of 36 points, ${ }^{22}$ a power of $80 \%$, and a two sided $\alpha$ of 0.05 , we needed 92 women in each treatment arm. Allowing for a dropout rate of $15 \%$, we needed a total of 216 women for this trial.

\section{Randomisation}

We used blocked randomisation with variable block sizes to randomise participants to one of the treatment arms in a one to one ratio. An independent statistician who was not involved in the enrolment of participants generated an allocation sequence. The research physician used an external computer system with an interactive voice response system (accessible by telephone) to enrol participants in the study. This research physician was blinded to allocation sequence and to both the ordering of the blocks and their sizes.

\section{Blinding}

Participants, pelvic physiotherapists, and research physicians were not blinded to group allocation. Research physicians and pelvic physiotherapists were blinded to all answers on the participant completed questionnaires, and research physicians were blinded to the outcomes of the previous POP-Q measurements and previous evaluations of pelvic floor muscle function.

\section{Statistical methods}

We compared the difference in the change of questionnaire scores (PFDI-20, Pelvic Floor Impact Questionnaire-7, Pelvic Organ Prolapse/Incontinence Sexual Function Questionnaire-12, physical and mental component summary scores of general quality of life) from baseline to follow-up between groups by analysis of covariance using the follow-up score as the dependent variable and baseline score, baseline POP-Q stage (1 or 2), and previous prolapse treatment (more than one year previously) (yes/no) as covariates. ${ }^{23}$ For the Pelvic Floor Impact Questionnaire-7 scores, we used a square root transformation to obtain a normal distribution of the residuals. We used logistic regression analysis to assess whether patient perceived improvement or worsening of symptoms, improvement or worsening of POP-Q stage, and improvement or worsening of pelvic floor muscle function (dependent variables) were predicted by randomisation group (independent variable). We applied a Bonferroni correction to correct the reported $\mathrm{P}$ values for multiple testing.

We defined improvement/worsening of the POP-Q stage as improvement or worsening of one or more POP-Q stages (calculated for each compartment). We defined improvement of pelvic floor muscle function as a change from abnormal (underactive/overactive/inactive) at baseline to normal at follow-up and worsening of pelvic floor muscle function as a change from normal at baseline to abnormal at follow-up. We imputed missing values in primary and secondary outcomes by multiple imputation. The imputation model was based on a missing value analysis and included the primary and secondary outcomes of the study and the following variables: treatment group, age, body mass index, parity, and previous prolapse treatment. We compared results of the analyses on the non-imputed dataset and analyses after multiple imputation to assess the effect of multiple imputation on the outcomes. We did all analyses according to the intention to treat principle. We used a $\mathrm{P}<0.05$ significance level for all statistical tests. We used SPSS Statistics for Windows, version 20.0, for the analyses.

\section{Results}

In total, 145 women were allocated to pelvic floor muscle training and 142 women to watchful waiting (figure $\Downarrow$ ). Table $1 \Downarrow$ shows the baseline characteristics of the study population. Follow-up questionnaires were completed by 250 (87\%) participants, and the follow-up appointment was attended by $237(83 \%)$. Median time from the start of treatment to completing the questionnaires was 3.6 (interquartile range 3.0-4.3) months for women in the pelvic floor muscle training 
group and 3.2 (3.2-3.6) months in the watchful waiting group. In total, 11 (8\%) participants did not receive pelvic floor muscle training and $19(13 \%)$ discontinued the intervention prematurely (figure $\downarrow$ ). For participants who completed the pelvic floor muscle training intervention, the median number of treatments was 7 (interquartile range 5-9). Myofeedback was used in 23 (16\%) participants, and electric stimulation was used in $11(8 \%)$. At follow-up, 59 (41\%) participants had not yet finished pelvic floor muscle training.

In the intention to treat analysis, participants in the pelvic floor muscle training group showed (on average) a 9.1 point greater improvement on the Pelvic Floor Distress Inventory-20 scale than participants in the watchful waiting group $(\mathrm{P}=0.005)$. For the subscales, the difference between pelvic floor muscle training and watchful waiting was significant on the Urinary Distress Inventory- 6 but not on the Pelvic Organ Prolapse Distress Inventory-6 or ColoRectal-Anal Distress Inventory-8. Sexual functioning (Pelvic Organ Prolapse/Incontinence Sexual Function Questionnaire-12) and the physical and mental component summary scores of general quality of life did not change over time. Condition specific quality of life (Pelvic Floor Impact Questionnaire-7) improved in both groups (difference not significant) (table $2 \Downarrow$ ). Of the participants in the pelvic floor muscle training group, 57\% reported an improvement in symptoms from the start of the study. In the watchful waiting group, improvement was reported by only $13 \%$, and $81 \%$ of the participants reported that their symptoms remained the same (table $3 \Downarrow$ ). The visual analogue scale scores of improvement/deterioration showed no significant difference between the groups (data not shown).

At follow-up, the proportion of participants with an improvement of one or more POP-Q stages showed no difference between the groups for any of the compartments (table $4 \Downarrow$ ). The proportion of women with deterioration of one or more POP-Q stages was also the same in both groups for all compartments. The proportion of women in whom pelvic floor muscle function improved from baseline to follow-up was the same in both groups in both the non-imputed and imputed datasets (non-imputed: pelvic floor muscle training 27/106 $(25 \%)$ versus watchful waiting 18/124 (15\%) (corrected $\mathrm{P}=0.117)$; imputed: pelvic floor muscle training 35/145 (24\%) versus watchful waiting $21 / 142(15 \%)$ (corrected $\mathrm{P}=0.213)$ ). The proportion of women in whom pelvic floor muscle function deteriorated between baseline and follow-up was the same in both groups (data not shown).

No participants reported any adverse effects of pelvic floor muscle training.

\section{Discussion}

Women with mild prolapse who received pelvic floor muscle training showed greater improvement in symptoms than did women randomised to a watchful waiting strategy. Although the difference between the groups (9.1 points) was significant, it was below the presumed level of clinical relevance ( 15 points). Nevertheless, $57 \%$ of women in the pelvic floor muscle training group reported symptomatic improvement compared with only $13 \%$ in the watchful waiting group. However, because this patient reported outcome may be susceptible to recall bias and social desirability bias, these results need to be interpreted with caution. Nevertheless, women receiving pelvic floor muscle training seemed to gain more insight into their symptoms and underlying condition, leading to a higher subjective appreciation of improvement than was reflected in the change in PFDI-20 scores. Another possibility is that a subgroup of women benefit from pelvic floor muscle training, whereas others do not experience any improvement. Further research might identify factors related to the success of pelvic floor muscle training. Typical symptoms of prolapse (such as seeing or feeling a vaginal bulge) are thought to emerge when the leading edge of the prolapse is at or below the hymen. ${ }^{45}$ Therefore, in women with mild prolapse, other common prolapse related symptoms, such as urinary and bowel symptoms, should be assessed. In this study, in women with mild prolapse, pelvic floor muscle training mainly affected the urinary symptoms. The largest difference in mean change from baseline was achieved in the PFDI-20 subscale measuring urinary symptoms (Pelvic Organ Prolapse Distress Inventory-6). The other PFDI-20 subscales (measuring prolapse and bowel symptoms) showed no significant differences in change between the groups. The relation between prolapse and urinary symptoms is not yet completely understood. Although stress urinary incontinence and prolapse are thought to be two coexisting problems that share causative factors rather than having a cause and effect relation, ${ }^{24}$ prolapse might cause bladder outlet obstruction, leading to irritable bladder symptoms (urgency, urge incontinence, frequency, nocturia) ${ }^{25}$ Stress urinary incontinence is more common in women with mild prolapse, ${ }^{26}{ }^{27}$ whereas irritable bladder symptoms are thought to be more common in women with advanced prolapse. ${ }^{25}$

\section{Strengths and limitations of study}

The main strengths of this study are its sample size, its pragmatic design with patient oriented outcome measures, and the fact that it is the first study to compare pelvic floor muscle training and watchful waiting in a primary care population of women with a symptomatic mild prolapse. The study also has some limitations. Because many women with prolapse symptoms do not consult a physician, ${ }^{28}$ we chose to screen women for symptoms possibly related to prolapse. Consequently, because some women in our study population experienced only mild symptoms at baseline, the mean PFDI-20 baseline score was lower than those reported in similar studies. This might have led to an underestimation of the effect of pelvic floor muscle training because little room for improvement exists when symptoms are mild at baseline.

Another limitation is that we did not use a standard pelvic floor muscle training protocol. Instead, we chose a pragmatic approach in which the participating pelvic physiotherapists tailored the treatment to the needs of each participant. To minimise the effect of any possible differences between pelvic physiotherapists as regards their experience or skills, the pelvic physiotherapists had to be registered with the Dutch Pelvic Physiotherapists' Organisation. As a consequence, all participants were trained according to the same basic exercise scheme. However, because we did not register the amount of home exercises performed by the participants, we do not know how strictly the participants adhered to their home exercise programme.

Women in the control group received no active treatment or recommendations. This choice was also pragmatic; because women with mild prolapse often do not qualify for pessary treatment or surgical correction, watchful waiting would be usual practice for many women with symptomatic mild prolapse. We do not know to what extent women in the watchful waiting group were influenced by the information they received about prolapse at baseline; better understanding of their condition (for example, knowing that they had a mild prolapse and what this means) and its treatment options might have led to an 
improvement in symptom burden. They may also have started doing pelvic floor home exercises by themselves; however, as this would also be the case in usual practice it is probably not a great disadvantage.

Finally, the effect of pelvic floor muscle training compared with watchful waiting was assessed after three months of treatment. However, as not all participants had finished pelvic floor muscle training at the moment of follow-up, the difference between the groups might increase as the maximal effect of pelvic floor muscle training had not yet been achieved. Also, rather than relieving symptoms, pelvic floor muscle training might prevent symptoms from getting worse. This implies that symptoms in the pelvic floor muscle training group would remain stable whereas those in the watchful waiting group would get worse over time; this might also apply to the degree of prolapse. However, the period of follow-up in this study was too short to establish such a difference between the groups. We found no difference in the change in pelvic floor muscle function between the groups; this might also be related to the duration of follow-up. Another possible explanation is that the method we used for measuring pelvic floor muscle function may not be sufficiently sensitive to small changes in pelvic floor muscle function. However, as the clinical relevance of these small changes is questionable, we think the method we used was appropriate.

\section{Comparison with other studies}

To date, only three small studies have evaluated the effect of pelvic floor muscle training on mild prolapse. Hagen et al reported a pilot study in which 47 women with a symptomatic stage 1-2 prolapse were randomised to pelvic floor muscle training $(n=23)$ or to a postal lifestyle advice sheet $(n=24){ }^{7}$ Stüpp et al reported a pilot study in which 37 women with a stage 2 prolapse were randomised to pelvic floor muscle training $(n=21)$ or control $(n=16)$; women in the control group did not consult a physiotherapist but received instructions on how to perform pelvic floor muscle contractions and a lifestyle advice leaflet. ${ }^{8}$ Ghroubi et al reported a trial in which 47 women with stage 1-2 prolapse of the anterior vaginal wall were randomised to pelvic floor muscle training $(n=27)$ or no treatment $(n=20) .{ }^{10}$ All three studies showed beneficial effects of pelvic floor muscle training on symptoms; however, as two of them were small pilot studies and the other was of moderate methodological quality, these results need to be confirmed in larger samples.

Furthermore, as all these studies were conducted in a hospital setting, their conclusions might not be generalisable to the primary care population.

More studies have investigated the effect of pelvic floor muscle training on more severe stages of prolapse. The most rigorous trial so far was by Hagen et al,${ }^{14}$ who randomised 447 women with symptomatic stage 1-3 prolapse to pelvic floor muscle training or a lifestyle leaflet. Follow-up was at six and 12 months, and participants could be referred for further treatment at six months. Pelvic floor muscle training led to a significantly greater reduction in prolapse symptoms, with a difference in mean change from baseline of 1.52 points on the Pelvic Organ Prolapse Symptom Score between the groups (minimal clinically important difference $=1 \cdot 5^{29}$ ). No difference was seen in improvement of bladder and bowel symptoms at 12 months. The results of this trial are probably not generalisable to the primary care population of women with mild prolapse (above the hymen), as participants were recruited in a hospital setting and $70 \%$ of them had an advanced prolapse (at or below the hymen). Two other trials compared pelvic floor muscle training with a control intervention. Braekken et al enrolled 109 women with stage 1-3 prolapse who attended a gynaecologist with prolapse symptoms or for a routine check-up and also women who were just interested to know if they had a prolapse. Women in the control group were advised to avoid straining and were taught how to contract their pelvic floor muscles before and during increases in abdominal pressure (the knack). ${ }^{11}$ Kashyap et al randomised 140 women with stage 1-3 prolapse who attended a gynaecology outpatient department with prolapse symptoms. Women in the control group received a self instruction manual with a home exercise programme but no sessions with a pelvic physiotherapist. ${ }^{12}$ In both studies, pelvic floor muscle training resulted in a greater improvement in symptoms than did the control intervention. However, because both studies included both asymptomatic women and women with more severe stages of prolapse, these results are probably also not generalisable to the primary care population of women with only mild prolapse. Finally, Piya-Anant et al randomised 320 women with mild or advanced prolapse to pelvic floor muscle training and 324 to control. ${ }^{13}$ Despite the sample size, this study had considerable methodological shortcomings, and, as it did not consider the effects of pelvic floor muscle training on symptoms, the results cannot be compared with those of our study.

\section{Clinical interpretation of results}

Although we found a significant difference between the groups, this difference is probably not clinically relevant. Very limited literature is available on the minimal clinically important difference for the PFDI-20 questionnaire in women with mild prolapse. In the design phase of this trial, we assumed a difference of 15 points between groups to be clinically relevant. The between treatment minimal clinically important difference can be defined as the difference between the mean change in PFDI-20 score in participants who report that their symptoms are "the same" and those who report that symptoms are "a little better" at follow-up compared with baseline. Gelhorn et al studied the psychometric properties of the PFDI-20 in two different populations of women undergoing prolapse surgery, with baseline scores of 114.8 and 97.1, and found between treatment minimal clinically important differences of 7.5 points and 17.3 points, respectively. ${ }^{30}$ Utomo et al studied the PFDI-20 in women with one or more pelvic floor symptoms who were recruited in a tertiary urology and gynaecology clinic. They found a between treatment minimal clinically important difference of 19 points in a subgroup of patients undergoing (conservative or surgical) treatment (baseline score 94.1 points: personal communication E Utomo, 5 June 2014).${ }^{31}$ However, as the minimal clinically important difference may vary by population and by context, ${ }^{32}$ these numbers might not be generalisable to our primary care study population in which PFDI-20 baseline scores were considerably lower.

We used a three point scale to assess patients' perceived change of symptoms from the start of the study (the same/better/worse). The difference in the change in PFDI-20 score between women who reported that symptoms were "the same" and those who reported that they were "better" was 15.2 points. On the basis of these findings, the difference between pelvic floor muscle training and watchful waiting found in our study does not seem to be clinically relevant. However, as the category "a little better" was not available in our questionnaire, the actual between treatment minimal clinically important difference of the PFDI-20 questionnaire in a primary care population might be lower. Therefore, we do not know for sure whether the detected difference of 9.1 points is clinically relevant in this population. 


\section{Conclusions and policy implications}

This is the first study to investigate the effects of pelvic floor muscle training in a primary care population of women with symptomatic mild prolapse, who were identified by screening. We found a significant but presumably not clinically relevant difference in the change in symptoms (PFDI-20) between the groups. Nevertheless, as $57 \%$ of the participants in the pelvic floor muscle training group reported that their symptoms had improved, pelvic floor muscle training might be considered for the treatment of women with bothersome symptomatic mild prolapse who do not qualify for pessary treatment or surgical correction. Further research might identify factors related to the success of pelvic floor muscle training. Additionally, more research on long term follow-up is needed to investigate whether the effects of pelvic floor muscle training are sustained on the long term and to establish whether pelvic floor muscle training can prevent symptomatic mild prolapse from getting worse.

We thank Aaltje Schram, Bert Messelink, Truuske De Bock, and Karin Vermeulen for their contributions to the design of this study. We also thank the participating general practices for their ongoing support and all the participants for their invaluable contribution to this study. Contributors: MW collected the data, did the analysis, and wrote the paper. CMCRP collected the data and contributed to the writing of the paper. BJK assisted with the analysis and contributed to the writing of the paper, MYB assisted in the study design and contributed to the writing of the paper. YL-VL assisted in the study design, assisted with the analysis, and contributed to the writing of the paper. JHD designed the study, was project leader, and contributed to the writing of the paper. JHD is the guarantor.

Funding: This trial is funded by the Netherlands Organization for Health Research and Development (ZonMw), project number 4201.1001. The funder played no role in the study design; in the collection, analysis, and interpretation of data; or in the writing of the report and the decision to submit the article for publication. All researchers were independent from funders.

Competing interests: All authors have completed the ICMJE uniform disclosure form at www.icmje.org/coi_disclosure.pdf (available on request from the corresponding author) and declare: no support from any organization for the submitted work; no financial relationships with any organizations that might have an interest in the submitted work in the previous three years; no other relationships or activities that could appear to have influenced the submitted work.

Ethical approval: The Medical Ethics Committee of the University Medical Centre Groningen (Netherlands) (METc2009.215) approved this study. All participants gave written informed consent.

Transparency declaration: The lead author (the manuscript's guarantor) affirms that the manuscript is an honest, accurate, and transparent account of the study being reported; that no important aspects of the study have been omitted; and that any discrepancies from the study as planned (and, if relevant, registered) have been explained.

Data sharing: No additional data available.

Haylen BT, de Ridder D, Freeman RM, Swift SE, Berghmans B, Lee J, et al. An International Urogynecological Association (IUGA)/International Continence Society (ICS) joint report on the terminology for female pelvic floor dysfunction. Neurourol Urodyn 2010;29:4-20.

2 Slieker-ten Hove MC, Pool-Goudzwaard AL, Eijkemans MJ, Steegers-Theunissen RP, Burger CW, Vierhout ME. The prevalence of pelvic organ prolapse symptoms and signs and their relation with bladder and bowel disorders in a general female population. Int Urogynecol J Pelvic Floor Dysfunct 2009;20:1037-45.

3 Nygaard I, Barber MD, Burgio KL, Kenton K, Meikle S, Schaffer J, et al. Prevalence of symptomatic pelvic floor disorders in US women. JAMA 2008;300:1311-6.

4 Gutman RE, Ford DE, Quiroz LH, Shippey SH, Handa VL. Is there a pelvic organ prolapse threshold that predicts pelvic floor symptoms? Am J Obstet Gynecol 2008;199:683.e1-7.
5 Swift S, Woodman P, O'Boyle A, Kahn M, Valley M, Bland D, et al. Pelvic Organ Support Study (POSST): the distribution, clinical definition, and epidemiologic condition of pelvic organ support defects. Am J Obstet Gynecol 2005;192:795-806.

6 Wu JM, Kawasaki A, Hundley AF, Dieter AA, Myers ER, Sung VW. Predicting the number of women who will undergo incontinence and prolapse surgery, 2010 to 2050. Am J Obstet Gynecol 2011;205:230.e1-5.

7 Hagen S, Stark D, Glazener C, Sinclair L, Ramsay I. A randomized controlled trial of pelvic floor muscle training for stages I and II pelvic organ prolapse. Int Urogynecol J Pelvic Floor Dysfunct 2009;20:45-51.

8 Stüpp L, Resende AP, Oliveira E, Castro RA, Girao MJ, Sartori MG. Pelvic floor muscle training for treatment of pelvic organ prolapse: an assessor-blinded randomized controlled trial. Int Urogynecol J 2011;22:1233-9.

9 Bo K. Can pelvic floor muscle training prevent and treat pelvic organ prolapse? Acta Obstet Gynecol Scand 2006:85:263-8.

10 Ghroubi S, Kharrat O, Chaari M, Ben Ayed B, Guermazi M, Elleuch MH. Effect of conservative treatment in the management of low-degree urogenital prolapse. Ann Readapt Med Phys 2008;51:96-102.

11 Braekken IH, Majida M, Engh ME, Bo K. Can pelvic floor muscle training reverse pelvic organ prolapse and reduce prolapse symptoms? An assessor-blinded, randomized, controlled trial. Am J Obstet Gynecol 2010;203:170.e1-7.

12 Kashyap R, Jain V, Singh A. Comparative effect of 2 packages of pelvic floor muscle training on the clinical course of stage I-III pelvic organ prolapse. Int $J$ Gynaecol Obstet 2013;121:69-73.

13 Piya-Anant M, Therasakvichya S, Leelaphatanadit C, Techatrisak K. Integrated health research program for the Thai elderly: prevalence of genital prolapse and effectiveness of pelvic floor exercise to prevent worsening of genital prolapse in elderly women. $J$ Med Assoc Thai 2003;86:509-15.

14 Hagen S, Stark D, Glazener C, Dickson S, Barry S, Elders A, et al. Individualised pelvic floor muscle training in women with pelvic organ prolapse (POPPY): a multicentre randomised controlled trial. Lancet 2014;383:796-806.

15 Wiegersma M, Panman CM, Kollen BJ, Vermeulen KM, Schram AJ, Messelink EJ, et al. Pelvic floor muscle training versus watchful waiting or pessary treatment for pelvic organ prolapse (POPPS): design and participant baseline characteristics of two parallel pragmatic randomized controlled trials in primary care. Maturitas 2014;77:168-73.

16 Messelink B, Benson T, Berghmans B, Bo K, Corcos J, Fowler C, et al. Standardization of terminology of pelvic floor muscle function and dysfunction: report from the pelvic floor clinical assessment group of the International Continence Society. Neurourol Urodyn 2005;24:374-80.

17 Bump RC, Mattiasson A, Bo K, Brubaker LP, DeLancey JO, Klarskov P, et al. The standardization of terminology of female pelvic organ prolapse and pelvic floor dysfunction. Am J Obstet Gynecol 1996;175:10-7.

18 Barber MD, Walters MD, Bump RC. Short forms of two condition-specific quality-of-life questionnaires for women with pelvic floor disorders (PFDI-20 and PFIQ-7). Am J Obstet Gynecol 2005;193:103-13.

19 Ware J Jr, Kosinski M, Keller SD. A 12-Item Short-Form Health Survey: construction of scales and preliminary tests of reliability and validity. Med Care 1996;34:220-33.

20 Ware JE, Kosinski M, Turner-Bowker DM, Gandek B. How to score version 2 of the SF-12 Health Survey (with a supplement documenting version 1). QualityMetric Incorporated, 2002.

21 Rogers RG, Coates KW, Kammerer-Doak D, Khalsa S, Qualls C. A short form of the Pelvic Organ Prolapse/Urinary Incontinence Sexual Questionnaire (PISQ-12). Int Urogynecol J Pelvic Floor Dysfunct 2003;14:164-8.

22 Culligan PJ, Scherer J, Dyer K, Priestley JL, Guingon-White G, Delvecchio D, et al. A randomized clinical trial comparing pelvic floor muscle training to a Pilates exercise program for improving pelvic muscle strength. Int Urogynecol J 2010;21:401-8.

23 Vickers AJ, Altman DG. Statistics notes: analysing controlled trials with baseline and follow up measurements. BMJ 2001;323:1123-4.

24 Smith PP, Appell RA. Pelvic organ prolapse and the lower urinary tract: the relationship of vaginal prolapse to stress urinary incontinence. Curr Urol Rep 2005;6:340-7.

25 De Boer TA, Salvatore S, Cardozo L, Chapple C, Kelleher C, van Kerrebroeck P, et al. Pelvic organ prolapse and overactive bladder. Neurourol Urodyn 2010;29:30-9.

26 Romanzi LJ, Chaikin DC, Blaivas JG. The effect of genital prolapse on voiding. J Urol 1999;161:581-6.

27 Burrows LJ, Meyn LA, Walters MD, Weber AM. Pelvic symptoms in women with pelvic organ prolapse. Obstet Gynecol 2004;104:982-8.

28 Thakar R, Stanton S. Management of genital prolapse. BMJ 2002;324:1258-62.

29 Hagen S, Glazener C, Cook J, Herbison P, Toosz-Hobson P. Further properties of the pelvic prolapse symptom score: minimally important change and test-retest reliability. Neurol Urodyn 2010;29:1055-6.

30 Gelhorn HL, Coyne KS, Sikirica V, Gauld J, Murphy M. Psychometric evaluation of health-related quality-of-life measures after pelvic organ prolapse surgery. Female Pelvic Med Reconstr Surg 2012;18:221-6.

31 Utomo E, Blok BF, Steensma AB, Korfage IJ. Validation of the Pelvic Floor Distress Inventory (PFDI-20) and Pelvic Floor Impact Questionnaire (PFIQ-7) in a Dutch population. Int Urogynecol J 2014:25:531-44.

32 Revicki D, Hays RD, Cella D, Sloan J. Recommended methods for determining responsiveness and minimally important differences for patient-reported outcomes. $J$ Clin Epidemiol 2008;61:102-9.

Accepted: 10 November 2014

\section{Cite this as: BMJ 2014;349:g7378}

This is an Open Access article distributed in accordance with the Creative Commons Attribution Non Commercial (CC BY-NC 4.0) license, which permits others to distribute, remix, adapt, build upon this work non-commercially, and license their derivative works on different terms, provided the original work is properly cited and the use is non-commercial. See: http://creativecommons.org/licenses/by-nc/4.0/. 


\section{What is already known on this topic}

Pelvic floor muscle training seems to be effective in relieving symptoms of prolapse in women with an advanced stage pelvic organ prolapse

High quality studies on the effectiveness of pelvic floor muscle training in women with symptomatic (mild) pelvic organ prolapse in a primary care setting are lacking

\section{What this study adds}

In women with mild pelvic organ prolapse, the change in symptom score after three months differed significantly between pelvic floor muscle training and watchful waiting/no treatment

However, the clinical relevance of this difference remains unclear

Women receiving pelvic floor muscle training were four times more likely to report a subjective improvement in overall symptoms than were women receiving no treatment

\section{Tables}

\begin{tabular}{|c|c|c|}
\hline Characteristics & Pelvic floor muscle training ( $n=145)$ & Watchful waiting $(n=142)$ \\
\hline Mean (SD) age, years & $64.5(6.8)$ & $64.0(6.5)$ \\
\hline Mean (SD) body mass index, $\mathrm{kg} / \mathrm{m}^{2}$ & $27.0(4.7)$ & $26.6(4.8)$ \\
\hline Mean (SD) parity & $2.4(1.2)$ & $2.4(1.1)$ \\
\hline Postmenopausal & $142(98)$ & $140(99)$ \\
\hline \multicolumn{3}{|l|}{ Educational level: } \\
\hline Primary only & $13(9)$ & $8(6)$ \\
\hline Lower & $51(35)$ & $51(36)$ \\
\hline Intermediate & $38(26)$ & $37(26)$ \\
\hline Higher & $43(30)$ & $46(32)$ \\
\hline \multicolumn{3}{|l|}{ Surgical history: } \\
\hline Hysterectomy & $30(21)$ & $24(17)$ \\
\hline Pelvic floor surgery & $13(9)$ & $6(4)$ \\
\hline Previous POP treatment $^{\star}$ & $25(17)$ & $18(13)$ \\
\hline \multicolumn{3}{|l|}{ Stage of POP†: } \\
\hline Stage 1 & $70(48)$ & $85(60)$ \\
\hline Stage 2 & $75(52)$ & $57(40)$ \\
\hline Type of POP: & $(n=144)$ & \\
\hline Anterior & $77(53)$ & $75(53)$ \\
\hline Posterior & $6(4)$ & $6(4)$ \\
\hline Apical & $1(1)$ & $1(1)$ \\
\hline Anterior and posterior & $30(21)$ & $31(22)$ \\
\hline Anterior and apical & $22(15)$ & $19(13)$ \\
\hline Posterior and apical & $2(1)$ & $4(3)$ \\
\hline Anterior and posterior and apical & $6(4)$ & $6(4)$ \\
\hline Mean (SD) PFDI-20 $\ddagger$ score & $65.2(39.9)$ & $59.0(32.2)$ \\
\hline Mean (SD) POPDI-6§ score & $15.5(13.4)$ & $13.6(12.4)$ \\
\hline Mean (SD) CRADI-8ף score & $17.2(15.3)$ & $16.2(14.4)$ \\
\hline Mean (SD) UDI- $6^{\star *}$ score & $32.4(19.7)$ & $29.4(15.8)$ \\
\hline
\end{tabular}

$\mathrm{POP}=$ pelvic organ prolapse

*Surgical or conservative POP treatment $>1$ year previously.

†Pelvic Organ Prolapse Quantification stage of most prolapsed compartment.

‡Pelvic Floor Distress Inventory-20 (range 0-300).

§Pelvic Organ Prolapse Distress Inventory-6 (range 0-100).

ๆColoRectal Anal Distress Inventory-8 (range 0-100).

${ }^{\star *}$ Urinary Distress Inventory-6 (range 0-100). 


\begin{tabular}{|c|c|c|c|c|c|c|}
\hline \multirow[b]{2}{*}{ Questionnaire } & \multicolumn{2}{|c|}{ Pelvic floor muscle training } & \multicolumn{2}{|c|}{ Watchful waiting } & \multicolumn{2}{|c|}{$\begin{array}{c}\text { Difference }(95 \% \mathrm{Cl}) \text { in mean change from } \\
\text { baseline }{ }^{\star} ; \mathrm{P} \text { value }\end{array}$} \\
\hline & Baseline score & Follow-up score & Baseline score & Follow-up score & Unimputed data & Imputed data \\
\hline PFDI-20† & $65.2(39.9) ; n=140$ & $46.9(37.4) ; n=117$ & $59.0(32.2) ; n=138$ & $51.3(29.7) ; n=127$ & $\begin{array}{c}-11.0(-16.6 \text { to }-5.4) \\
<0.0001\end{array}$ & $\begin{array}{c}-9.1(-15.4 \text { to }-2.8) \\
0.005\end{array}$ \\
\hline POPDI-6‡ & $15.5(13.4) ; n=145$ & 10.5 (12.3); $\mathrm{n}=118$ & $13.6(12.4) ; n=141$ & $11.4(11.3) ; n=129$ & $\begin{array}{l}-2.6(-4.9 \text { to }-0.4) \\
0.024\end{array}$ & $\begin{array}{c}-2.0(-4.5 \text { to } 0.5) \\
0.110\end{array}$ \\
\hline CRADI-8§ & $17.2(15.3) ; n=144$ & $13.7(15.3) ; n=118$ & $16.2(14.4) ; n=140$ & $13.6(12.7) ; n=128$ & $\begin{array}{l}-1.4(-3.7 \text { to } 0.8) \\
0.209\end{array}$ & $\begin{array}{c}-1.8(-4.3 \text { to } 0.7) \\
0.165\end{array}$ \\
\hline UDI-6ף & $32.4(19.7) ; n=141$ & 22.8 (17.2); $n=118$ & $29.4(15.8) ; n=140$ & $26.3(15.5) ; n=129$ & $\begin{array}{l}-6.0(-9.1 \text { to }-2.9) \\
<0.0001\end{array}$ & $\begin{array}{l}-5.0(-8.6 \text { to }-1.4) \\
0.007\end{array}$ \\
\hline PFIQ-7** & $22.1(39.9) ; n=139$ & $18.0(36.1) ; n=110$ & $12.1(17.9) ; n=131$ & $11.7(23.7) ; n=120$ & $\begin{array}{c}0.04(-0.1 \text { to } 0.5) \\
0.441\end{array}$ & $\begin{array}{c}0.03(-0.5 \text { to } 1.1) \\
0.478\end{array}$ \\
\hline PISQ-12†† & $35.5(5.3) ; n=64$ & $35.5(6.4) ; n=43$ & $36.4(5.4) ; n=70$ & $37.1(4.6) ; n=58$ & $\begin{array}{c}0.2(-1.1 \text { to } 1.5) \\
0.715\end{array}$ & $\begin{array}{c}-0.1(-2.3 \text { to } 2.1) \\
0.925\end{array}$ \\
\hline PCS-12ł‡ & $45.1(10.5) ; n=122$ & 46.5 (10.3); $n=111$ & 46.8 (9.7); $n=130$ & $46.6(10.4) ; n=121$ & $\begin{array}{c}1.5(-0.4 \text { to } 3.5) \\
0.125\end{array}$ & $\begin{array}{c}0.6(-1.8 \text { to } 3.0) \\
0.606\end{array}$ \\
\hline MCS-12§§ & 52.7 (8.5); n=122 & $53.4(7.1) ; n=111$ & 52.8 (8.5); $n=130$ & 53.7 (8.3); n=121 & $\begin{array}{c}-0.6(-2.3 \text { to } 1.0) \\
0.446\end{array}$ & $\begin{array}{c}-0.9(-2.7 \text { to } 0.8) \\
0.307\end{array}$ \\
\hline $\begin{array}{l}\text { *Adjusted for bas } \\
\text { †Pelvic Floor Dis } \\
\text { †Pelvic Organ Pr } \\
\text { §ColoRectal Anal } \\
\text { †Urinary Distress } \\
\text { **Pelvic Floor Imp } \\
\text { ††Pelvic Organ P } \\
\text { imputed only for } \\
\text { ††Physical Comp } \\
\S \S \text { Mental Compo }\end{array}$ & $\begin{array}{l}\text { seline score, baseline } \\
\text { tress Inventory-20 } \\
\text { rolapse Distress Inve } \\
\text { I Distress Inventory- } \\
\text { Inventory-6 (range } \\
\text { pact Questionnaire- } \\
\text { Drolapse/Incontinenc } \\
\text { women who were se } \\
\text { ponent Health Summ } \\
\text { onent Health Summa }\end{array}$ & $\begin{array}{l}\text { e Pelvic Organ Prola } \\
\text { range } 0-300) \text {. } \\
\text { entory-6 (range } 0-10 \\
-8 \text { (range } 0-100) \text {. } \\
0-100) . \\
7 \text { (range } 0-300) \text {. } \\
\text { ce Sexual Function } \\
\text { exually active at base } \\
\text { nary (SF-12); } 1998 \text { n } \\
\text { ary (SF-12). }\end{array}$ & $\begin{array}{l}\text { laire-12 (range 0-48) } \\
\text { ed scores. }\end{array}$ & ) (available only for $\mathrm{v}$ & רo were sexually active; & missing scores were \\
\hline
\end{tabular}


Table 3| Self reported change in symptoms from start of study. Values are numbers (percentages) unless stated otherwise

Unimputed data

Change PFMT ( $n=115)$ Watchful waiting $(n=124)$ P value*

Better $\quad 70(61)<10(8)<0.001$

Same $\quad 43(37) \quad 106(85) \quad<0.001$

Worse $\quad 2(2) \quad 0.270$

PFMT=pelvic floor muscle training

*Logistic regression analysis, corrected $\mathrm{P}$ value (Bonferroni).

†Owing to multiple imputation, percentages do not add up to $100 \%$.

Imputed data

PFMT† ( $n=145)$ Watchful waiting† ( $n=142)$ P value $^{*}$

\begin{tabular}{cccc}
.001 & $82(57)$ & $18(13)$ & $<0.001$ \\
\hline .001 & $58(40)$ & $115(81)$ & $<0.001$ \\
\hline 270 & $16(11)$ & $17(12)$ & 1.000 \\
\hline
\end{tabular}


Table 4| Number (\%) of participants with improvement of 1 or more Pelvic Organ Prolapse Quantification stages

\begin{tabular}{lllll} 
Compartment & Data & Pelvic floor muscle training & Watchful waiting & P value* \\
Anterior & Unimputed & $29 / 107(27)$ & $20 / 128(16)$ & 0.099 \\
\cline { 2 - 5 } & Imputed & $39 / 145(27)$ & $24 / 142(17)$ & 0.222 \\
\hline \multirow{2}{*}{ Posterior } & Unimputed & $10 / 106(9)$ & $14 / 128(11)$ & 1.000 \\
\cline { 2 - 5 } & Imputed & $13 / 145(9)$ & $14 / 142(10)$ & 1.000 \\
\hline \multirow{2}{*}{ Apical } & Unimputed & $15 / 107(14)$ & $20 / 127(16)$ & 1.000 \\
\cline { 2 - 5 } & Imputed & $23 / 145(16)$ & $22 / 142(15)$ & 1.000 \\
\hline
\end{tabular}

*Logistic regression analysis, corrected $\mathrm{P}$ value (Bonferroni). 
Figure

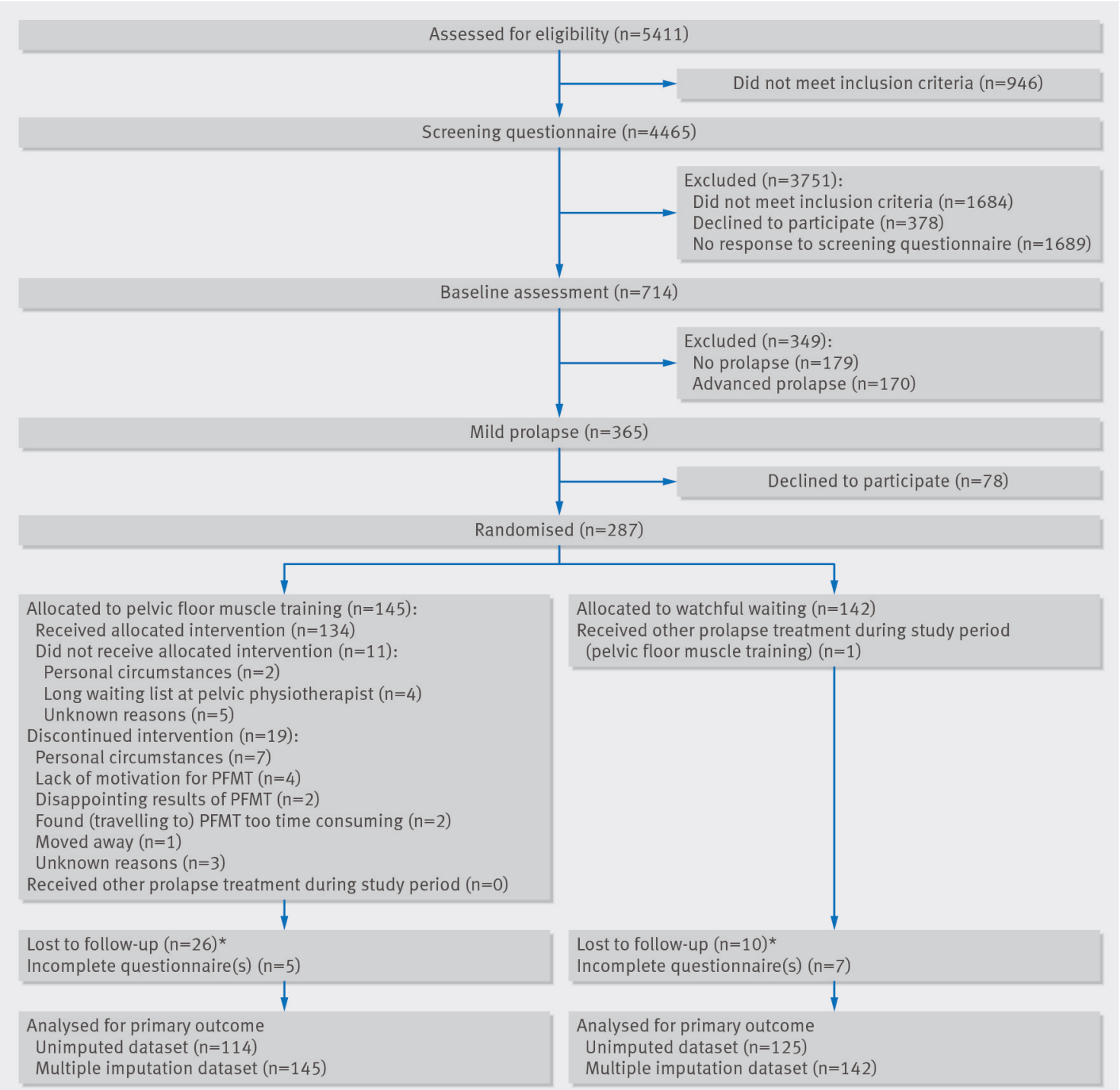

Flow of participants through study. PFMT=pelvic floor muscle training. *No follow-up questionnaire available 